\title{
Penile and intramuscular metastases from esophageal squamous cell carcinoma: A rare case report and review of the literature
}

\author{
Zou Ci, MD; Yu Dexin, MD; Wang Qi, MM; Zhang Tao, MD; Xie Dongdong, MD; Wang Yi, MD; \\ Ding Demao, MD; Chen Lei, MD; Min Jie, MD; Zhang Zhiqiang, MM; Ma Jiaxing, MM; Wang Daming, MM
}

Department of Urology, The Second Affiliated Hospital of Anhui Medical of University, Hefei, China

Cite as: Can Urol Assoc J 2014;8(11-12):e875-7. http://dx.doi.org/10.5489/cuaj.2253

Published online November 24, 2014.

\section{Abstract}

We present a case with penile and intramuscular metastases of esophageal squamous cell carcinoma. A 61-year-old male had undergone a total esophagectomy and later developed metastatic nodules of the penis and intramuscular metastasis of the thigh. We believe this is the first report of this rare case. We describe the clinical manifestation and offer therapeutic regimen; we also summarize the relevant literature.

\section{Introduction}

Metastasis to the penis is rare. In total, 437 cases have been reported as of $2011 .^{1}$ It usually originates from genitourinary $(75 \%)$ and gastrointestinal tract tumours $(18.6 \%)$. The most common symptoms and signs in order of frequency are priapism, urinary retention, penile nodules, ulcer formation, perineal pain, edema, generalized swelling, broad infiltrative enlargement, dysuria, and hematuria. ${ }^{2}$ Our patient presented with penile nodule and intramuscular mass in the thigh, which is extremely rare. The patient was offered systematic chemotherapy and local radiotherapy and got partial relief.

\section{Case report}

A 61-year-old male was hospitalized for progressive dysphagia for more than a month. He was diagnosed with esophageal carcinoma by gastroscopy and had undergone a total esophagectomy 6 months earlier. Postoperative histopathological examination revealed a moderated differentiated squamous cell carcinoma of the middle esophagus with infiltration of the adventitia. The resection margin was focally negative. Of the 8 lymph nodes resected, 1 showed metastasis. Also a cancerous nodule was found in the esophageus. The clinical stage was pT3pN1. He was administered 2 cycles of chemotherapy, as per the DLF regimen (conventional fractionated radiotherapy plus cisplatin [DDP] $20 \mathrm{mg}$ on day 1 to 5 + leucovorin [CF] $0.1 \mathrm{~g}$ day 1 to $5+5$-fluorouracil [5-FU] $0.5 \mathrm{~g}$ day 1 to 5 ). Three months earlier, he had multiple enlarged lymph nodes in his left neck. A biopsy confirmed metastatic moderated differentiated squamous cell carcinoma, consistent with his primary tumour. At this time, the patient started a new chemotherapy regimen (Taxol + nedaplatin I) with concomitant radiotherapy. At the end of external beam radiotherapy, all enlarged lymph nodes disappeared.

One month later, he was admitted to our hospital complaining about a painless mass in the right thigh and a gradually increasing nodule on the penis shaft. Physical examination revealed a $4 \times 5-\mathrm{cm}$, hard, fixed, non-tender mass in the right thigh and a hard nodule over the dorsal aspect of the penile shaft (Fig. 1). A computed tomography scan demonstrated metastasis of liver. A magnetic resonance image (MRI) showed a metastatic mass in the muscle of the right thigh (Fig. 2) and a penile nodular lesion measured $1.5 \times 1.5-\mathrm{cm}$ in size, occupying the left corpus cavernosum of the penis (Fig. 3). A needle puncture biopsy of the mass in the thigh revealed squamous cell carcinoma (Fig. 4). Excisional biopsy of the nodules on the penis demonstrated moderated differentiated squamous cell carcinoma (Fig. ), both all consistent with his primary esophageal tumour. The patient was in a chemotherapy refractory and systemic disseminated state. As a result of his poor performance status (severe anemia and lack of appetite), he was administered palliative external beam radiation (6000 cGy, 30 fractions) for the mass in the thigh. At the end of radiation (30 times), the mass decreased a third in size and he was discharged without other discomfort except for his lack of appetite and strength. After 5 months, he died from his illness. 


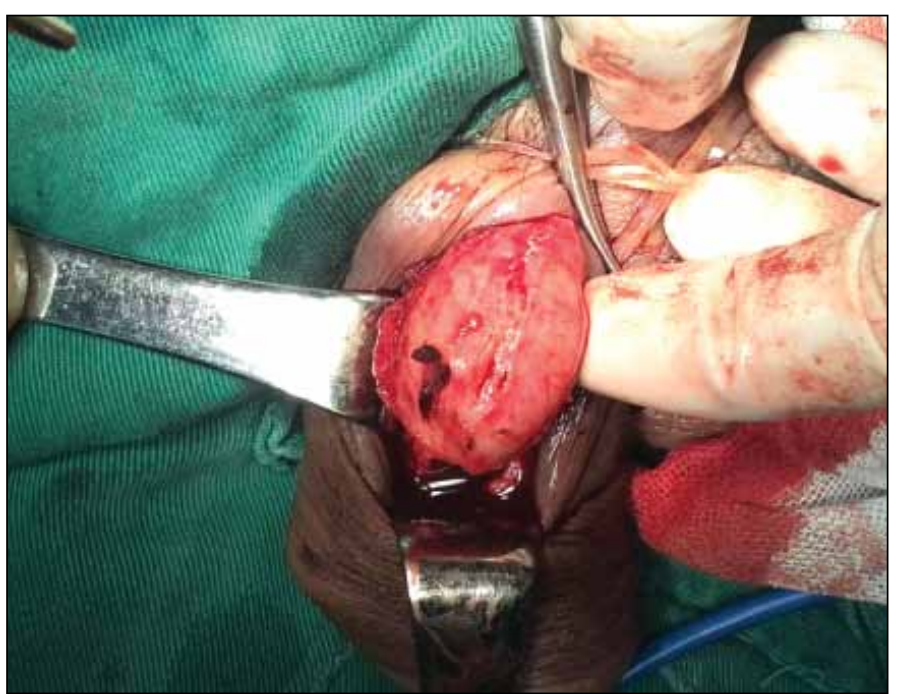

Fig. 1. The nodule was hard over the dorsal aspect of the penile shaft.

\section{Discussion}

Esophageal carcinoma is fatal, with a median 5-year survival of $20 \%$ to $40 \%$ in cases that curative resection can be performed for locally advanced diseases. Hematogenous spread results in distant metastasis after supra-radical resections. The most often distant organ involved is lung, followed by skeleton, and liver. The penis is a rare metastatic site. To date, there are only 3 cases of penile metastasis of an esophageal origin in the English literature. In addition, esophageal cancer rarely metastasizes to skeletal muscle. ${ }^{3}$

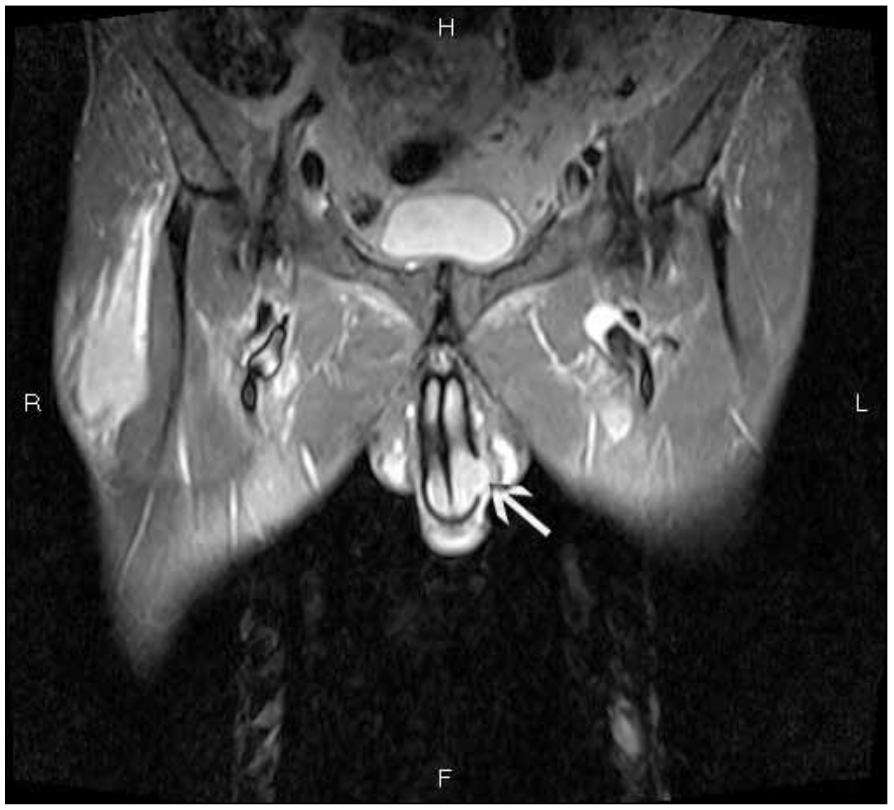

Fig. 3. Axial magnetic resonance image showed metastatic nodule of the penis (arrow).

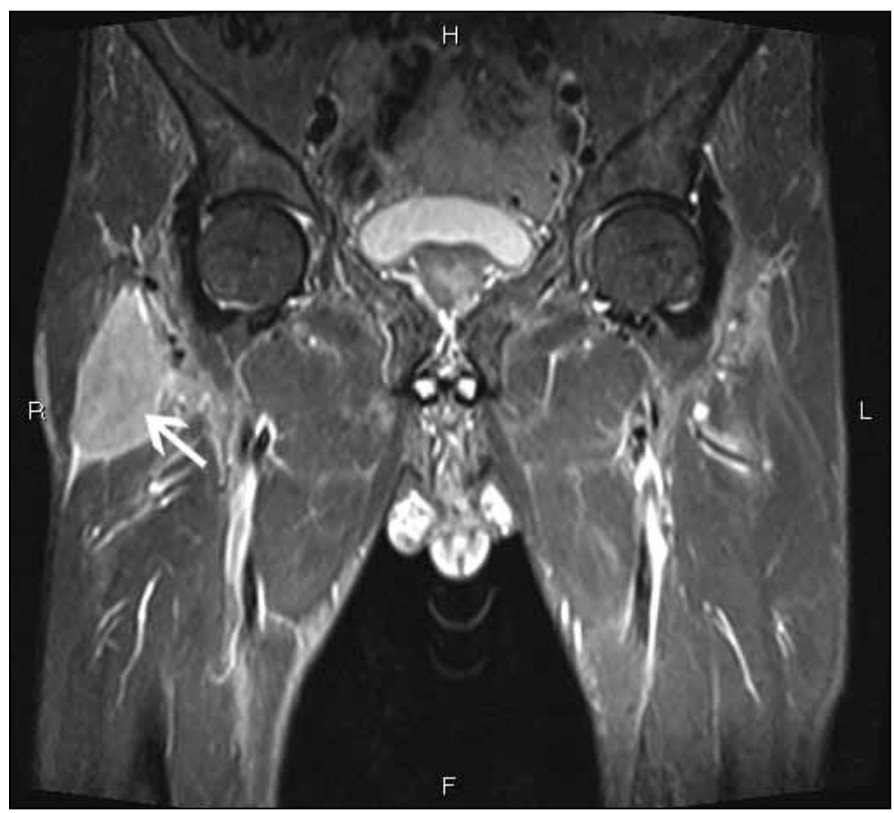

Fig. 2. Axial magnetic resonance image showed metastatic mass in the right thigh (arrow).

Our patient had metastasis on both sites simultaneously - an extremely rare occurrence. This type of metastasis is not only associated with tumour stage, but also with the tumour's oncologic behaviour. ${ }^{4}$

The prostate $(30.4 \%)$ and the bladder $(29.1 \%)$ are the primary sites of origin for secondary penile carcinoma, followed by the colon-rectum (16.9\%). ${ }^{1}$ Extra-pelvic sites

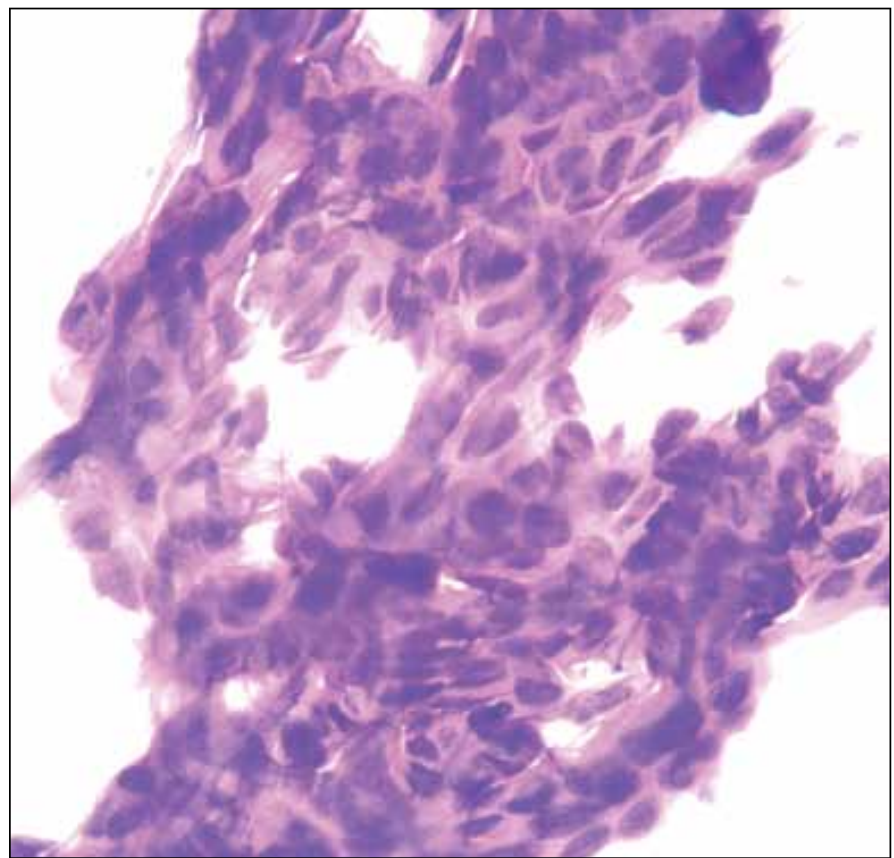

Fig. 4. Biopsy specimen of the mass on the right thigh showing metastatic squmaous cell carcinoma (hematoxylin and eosin stain $\times 400$ ). 


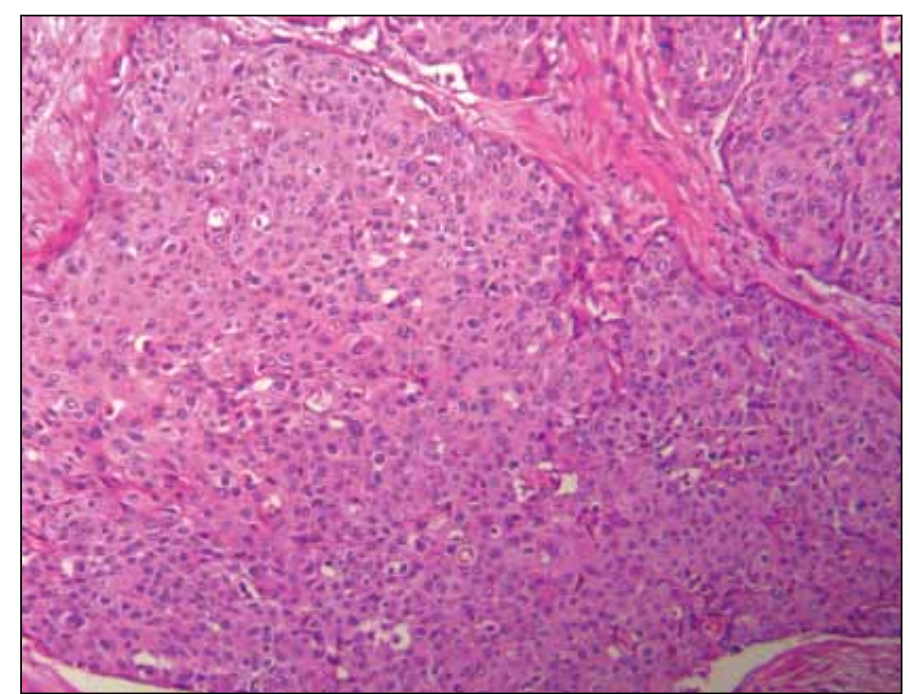

Fig. 5. Excisional biopsy of the penile nodule showing groups of metastatic carcinoma cells (hematoxylin and eosin stain $\times 400$ ).

include testis, pancreas, stomach, esophagus, anal canal, tongue, lungs, and bone. Several mechanisms for penile metastasis have been proposed. They include retrograde venous spread, retrograde lymphatic spread, arterial embolism spread, and local direct extension. ${ }^{5}$ Due to the generous communication between pelvic venous plexuses and dorsal venous system, retrograde venous spread is considered the most possible mechanism. Lymphatics of the penis and parts of the pelvic organs drain together into iliac lymph nodes directly or indirectly. In view of the anatomical proximity of prostate, bladder, and colon-rectum, direct tumour extension is considered another mechanism for spread. Arterial spread is rare, and is usually associated with widely disseminated disease. ${ }^{6}$ latrogenic spread, secondary to instrumentation, is possible in theory, but only can explain several rare cases. ${ }^{1,7}$ Intramuscular metastasis of esophageal squamous cell carcinoma is also rare event despite its rich blood supply. Some authors attribute it to constant movement of the muscle and lactic acid produced by the muscle which is bad for the growth of metastases. ${ }^{8}$ For our case, we believe the most possible mechanism is hematogenous spread.

Although the patient's cancer spread, he was asymptomatic. Imageology examination played an important role in the diagnosis. MRI is considered the best diagnostic imaging method because it can assess tumour extent at the tunica albuginea or urethra level for penile metastasis $;{ }^{9}$ it can also obtain details of the intramuscular metastasis. A positron emission tomography scan can improve the assessment of distant metastases after surgery and can detect clinically silent sites of recurrence. ${ }^{10}$ Definitive diagnosis should rely on biopsy or resection.
The differential diagnosis should also consider primary penile tumour or Peyronie's disease and myoma in the muscle. The prognosis is poor for most metastatic penile tumour from esophageal squamous cell carcinoma. Our patient died 5 months after the diagnosis of distant metastases. Unfortunately, there is no standard treatment modality for these patients. Our patient did not respond to chemotherapy and had partial response to radiotherapy.

\section{Conclusion}

Penile and intramuscular metastasis of esophageal squamous cell carcinoma is extremely rare. Patients with esophageal squamous cell carcinoma need careful follow-up; distant metastasis may present in many forms and some rare metastatic sites should also be considered.

Competing interests: Dr. Ci, Dr. Qi, Dr. Tao, Dr. Dongdong, Dr. Yi, Dr. Demao, Dr. Lei, Dr. Jie, Dr. Zhiqiang, Dr. Jiaxing, Dr. Daming and Dr. Dexin all declare no competing financial or personal interests.

This paper has been peer-reviewed.

\section{References}

1. Chaux A, Amin M, Cubilla AL, et al. Metastatic tumors to the Penis: A report of 17 cases and review of the literature. Int I Surg Pathol 2011;19:597-606. hittp://dx.doi.org/10.1177/1066896909350468

2. Pastore AL, Palleschi $G$, Manfredonia $G$, et al. Penile metastasis from primary cholangiocarcinoma: The first case report. BMC Gastroenterol 2013;13:1-5. http://dx.doi.org/10.1186/1471-230X-13-149

3. Cincibuch J, Myslive ek M, Melichar B, et al. Metastases of esophageal carcinoma to skeletal muscle: Single center experience. World I Gastroenterol 2012;18:4962.

4. Lerut T, Nafteux P, Moons J, et al. Three-field lymphadenectomy for carcinoma of the esophagus and gastroesophageal junction in $174 \mathrm{RO}$ resections: impact on staging, disease-free survival, and outcome: A plea for adaptation of TNM classification in upper-half esophageal carcinoma. Ann Surg 2004;240:962. http://dx.doi.org/10.1097/01.sla.0000145925.70409.d7

5. Cherian J, Rajan S, Thwaini A, et al. Secondary penile tumours revisited. Int Semin Surg Oncol 2006;3:33. http://dx.doi.org/10.1186/1477-7800-3-33

6. Yildiz BI, Fidan E, Yildiz K, et al. Penile metastasis from adenocarcinoma of the prostate in a patient with colorectal carcinoma. Acta Dermatovenerol Croat 2011;19:36-8.

7. Hizli F, Berkmen F. Penile metastasis from other malignancies. A study of ten cases and review of the literature. Urol Int 2006;76:118-121. http://dx.doi.org/10.1159/000090872

8. Sudo A, Ogihara Y, Shiokawa Y, et al. Intramuscular metastasis of carcinoma. J Clin Orthop 1993;19:213-7.

9. Kendi T, Batislam E, Basar MM, Yilmaz E, Altinok D, Basar H. Magnetic resonance imaging (MRI) in penile metastases of extragenitourinary cancers. Int Urol Nephrol 2006;38:105-9. http://dx.doi. org/10.1007/s 1 1255-005-0256-7

10. Pai A, Sonawane $S$, Purandare NC, et al. Penile metastasis from esophageal squamous carcinoma after curative resection. Ann Thorac Cardiovasc Surg 2008;14:238-41.

Correspondence: Dr. Ci Zou, Department of Urology, The Second Affiliated Hospital of Anhui Medical of University, Hefei, China; zci2003@qq.com 